\title{
PROBLEMS IN PSYCOLOGICAL EXPERT EXAMINATION OF CIVIL CASES
}

Arakelyan A.D., Sargsyan L. K. (Armenian State Pedagogical University, Yerevan, Armenia) araqelyananna23@aspu.am,sargsyanlevon23@aspu.am

乙tinцшјшgर्üи uर्u. 26.07.2021

9pmpunuर्uाe шर्रu. 10.08.2021

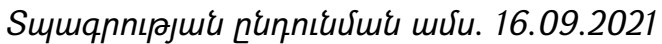

The paper attempts at presenting the existing problems in the field of forensic psychological examinations in civil cases, which complicate, and in some cases hinder the effective process of psychological examinations. In particular, the paper discusses legal and psychological grounds for appointting a forensic psychological examination in civil cases, professional uncertainties in the examination questions, existing difficulties and issues related to their solution as well as involvement of the parties in the examination.

Keywords: forensic psychological examination, psychologist-expert, expert issues, examinee, civil cases, parties to the trail.

DOI: https://doi.org/10.46991/SBMP/2022.5.1.011

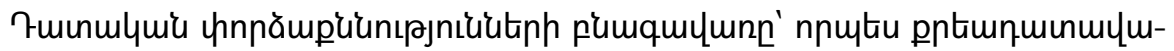

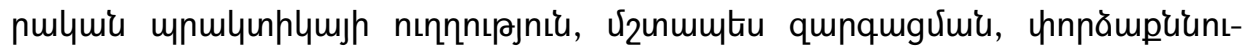

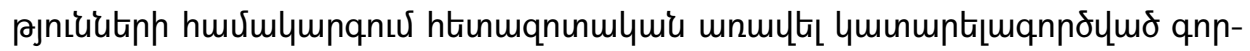

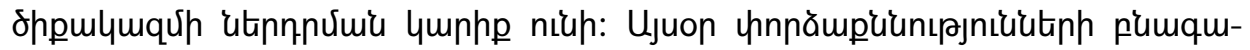

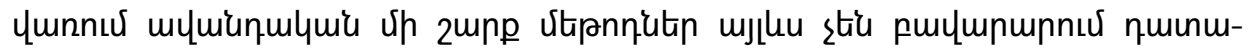

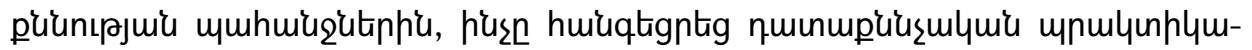

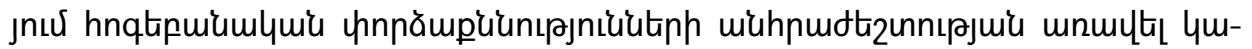

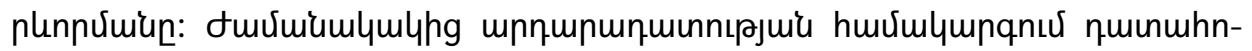

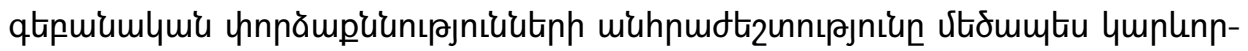
प

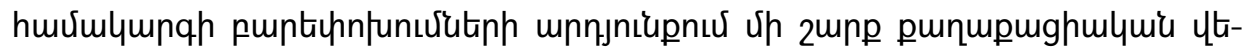

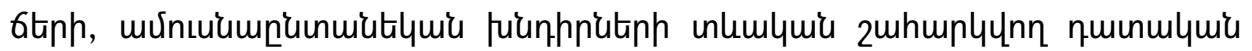

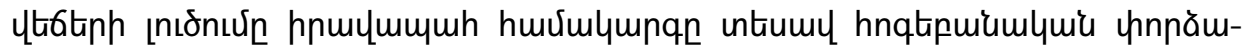

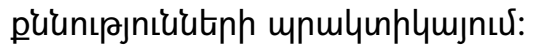

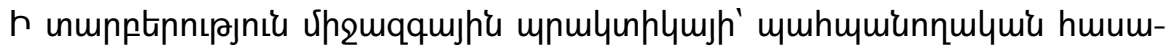

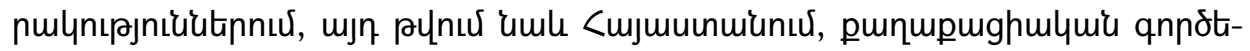

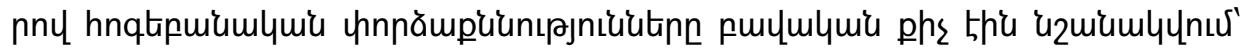

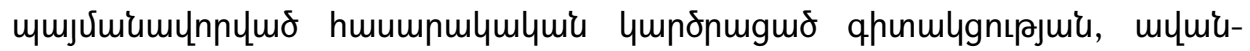

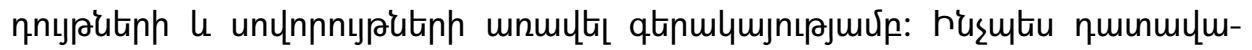

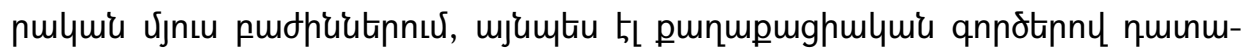




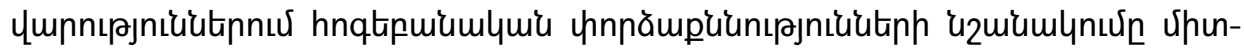
Ч

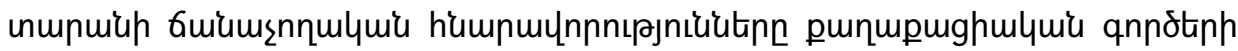

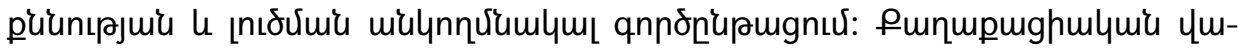

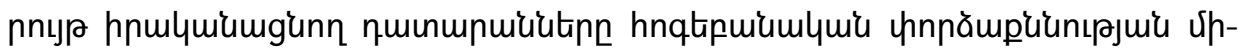

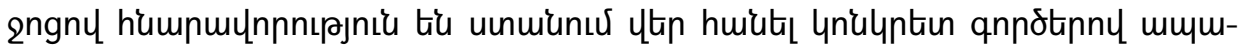

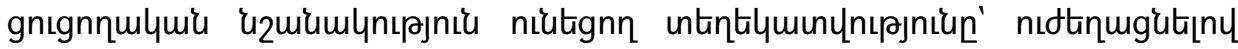

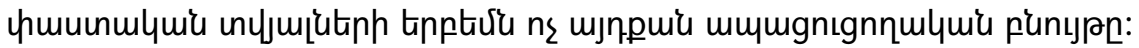

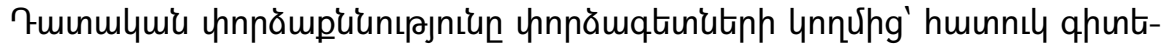

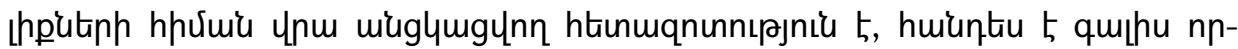

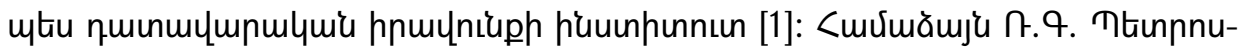

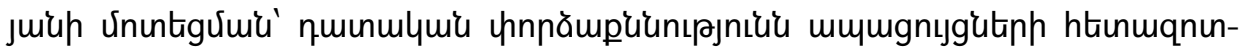

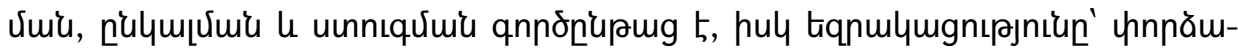

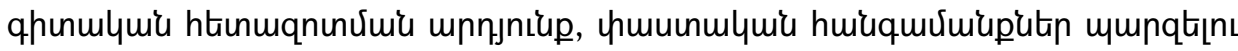
quinuulumulymiu ungeng [2]:

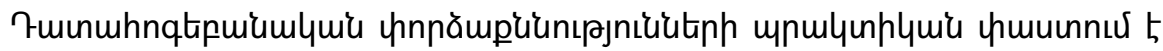

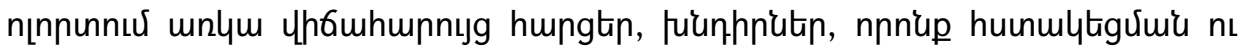
62qnunumiu yunhp niutiu:

7puiughg tiu.

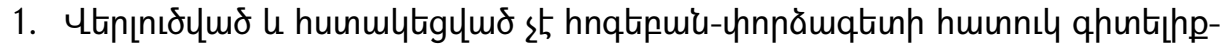

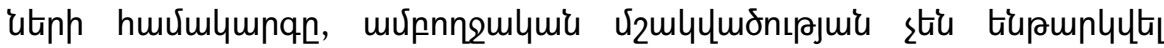

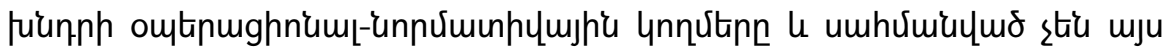

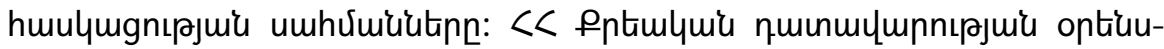

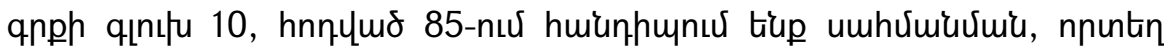

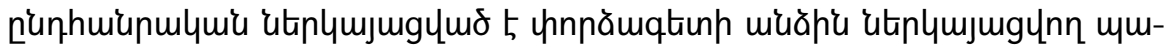

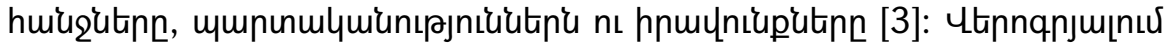

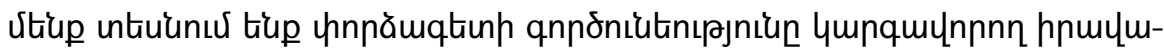

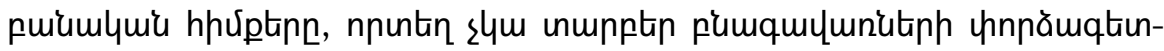

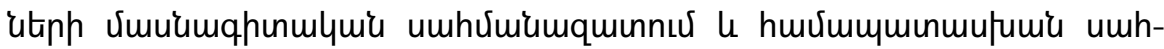
umuititin:

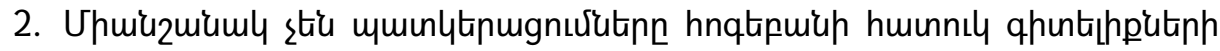

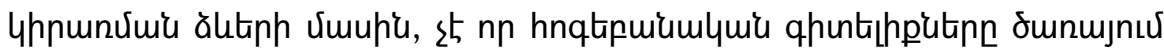

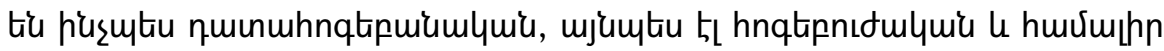

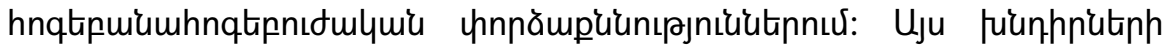

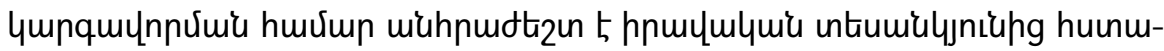

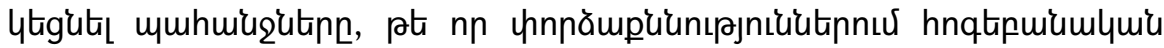

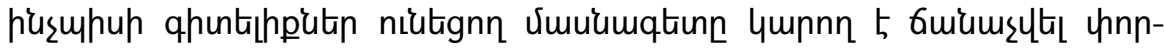

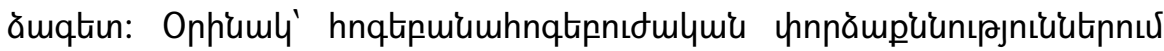

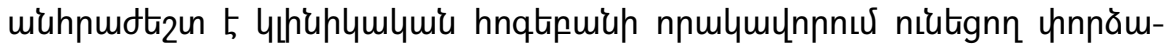
qtinh nunqulynuñ: 


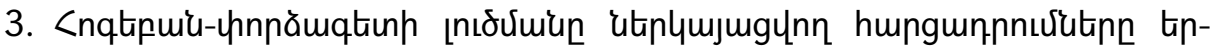

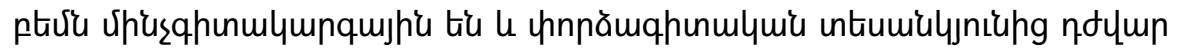

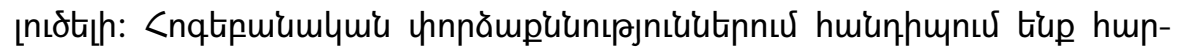

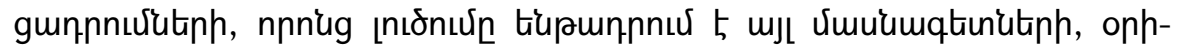

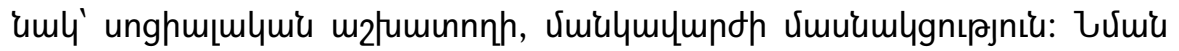

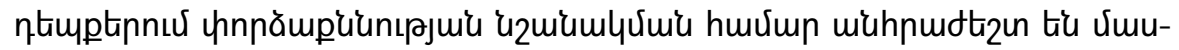
umqhunulymí paumunlynưutin:

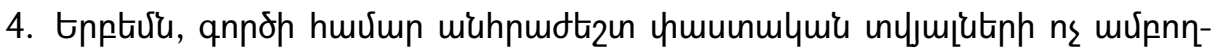

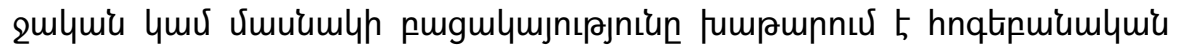

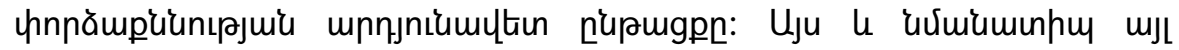

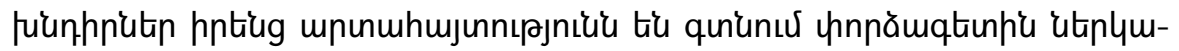

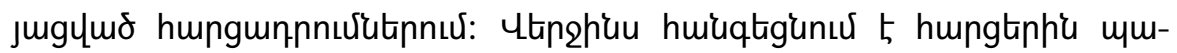

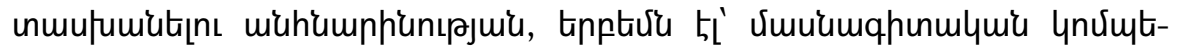

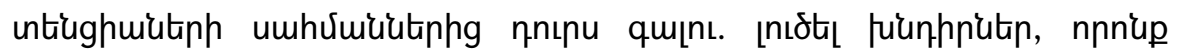

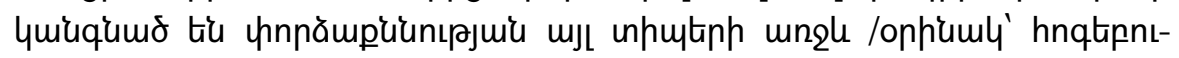

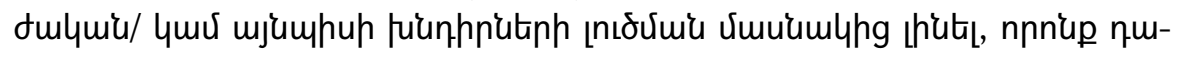

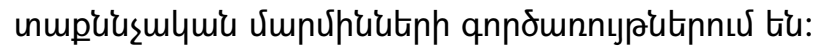

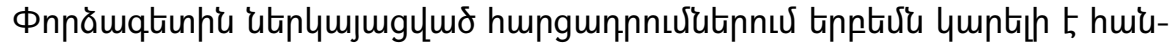

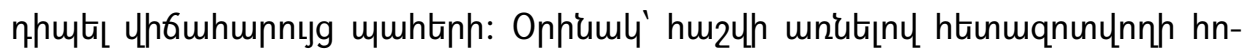

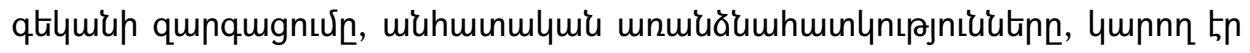

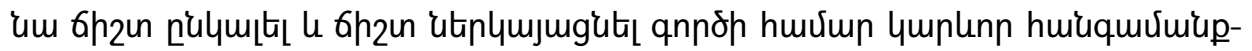

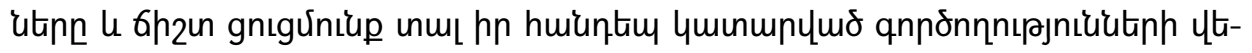

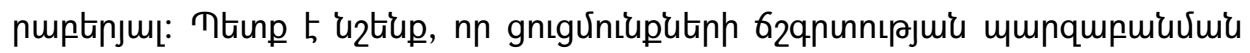

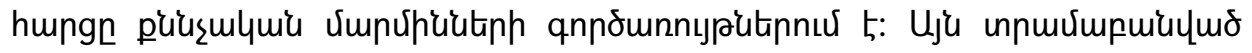

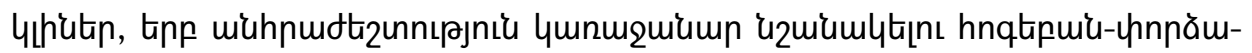

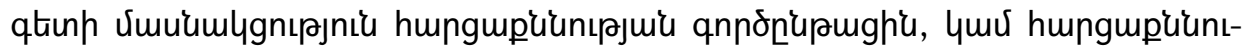

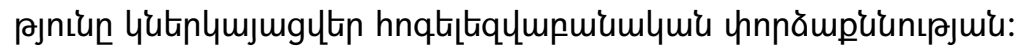

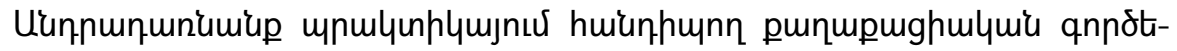

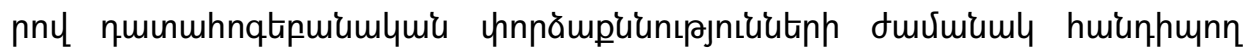
nnn2 tüunprititnh.

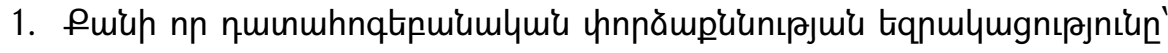

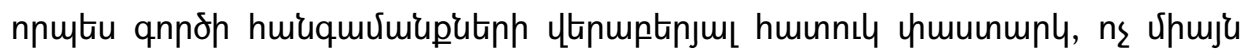

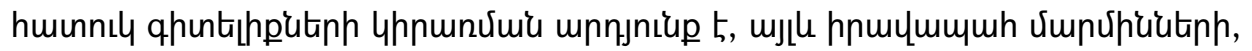

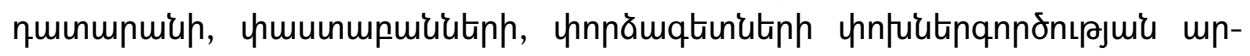

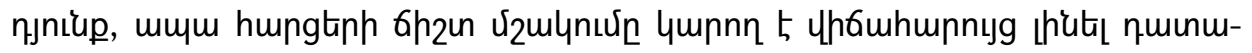

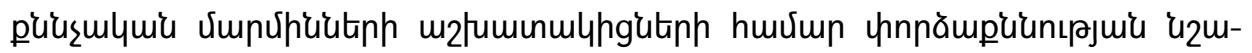

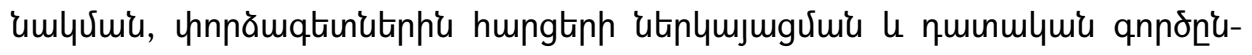

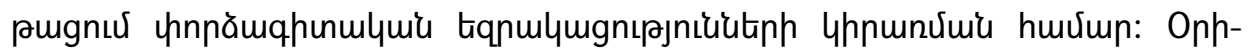

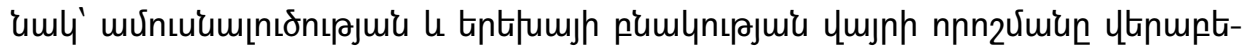

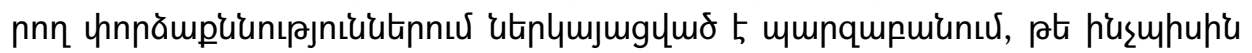




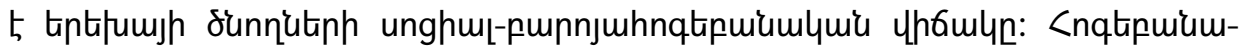

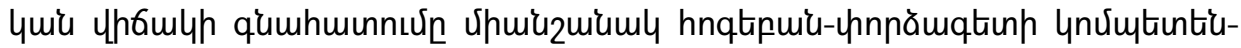

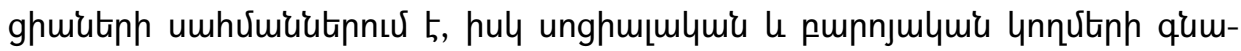

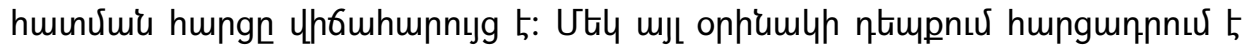

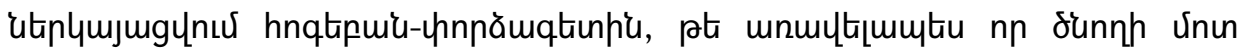

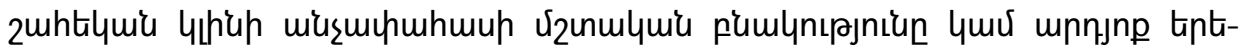

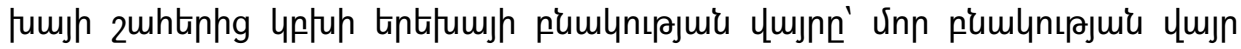

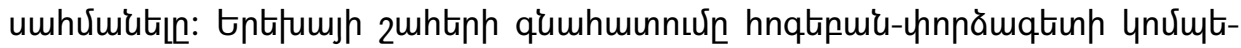

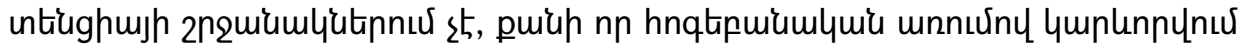

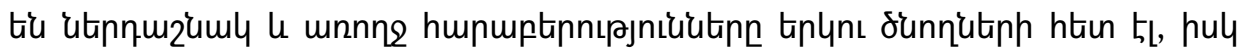

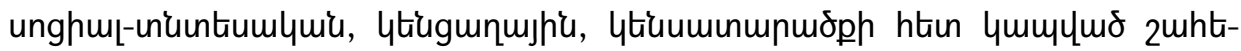

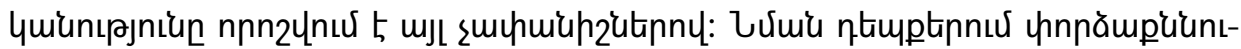

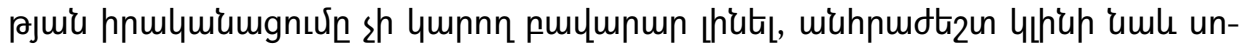

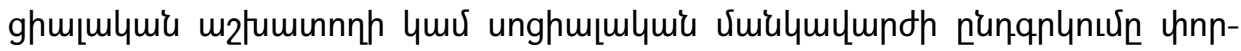

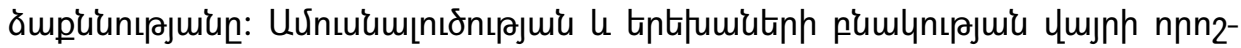

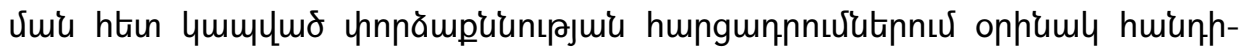

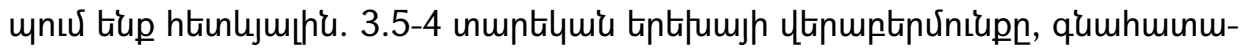

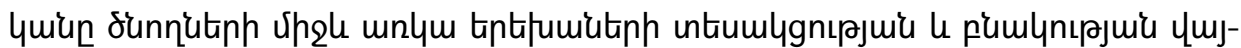

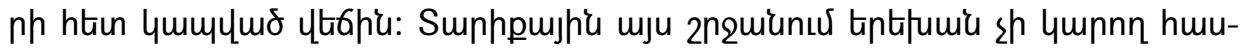

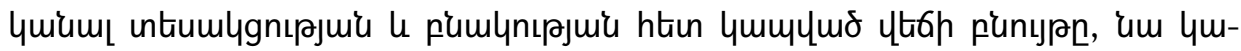

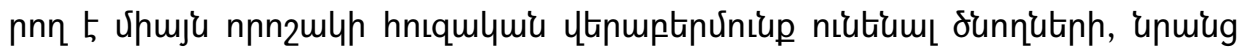

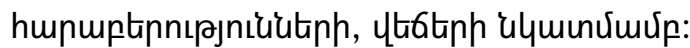

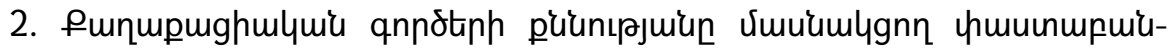

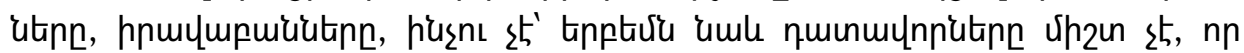

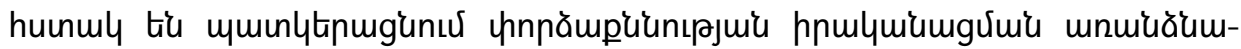

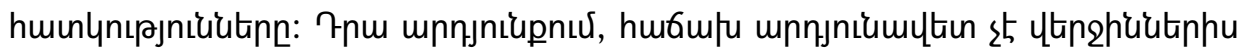

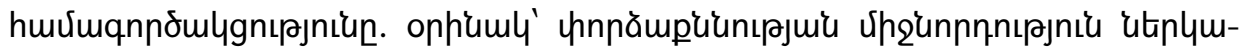

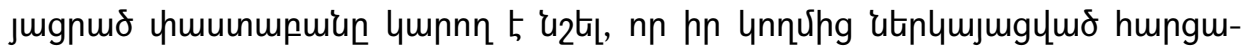

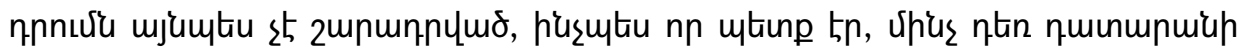

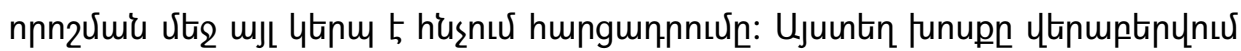

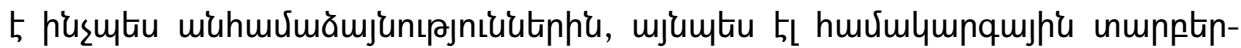

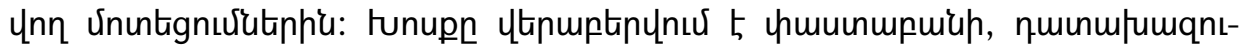

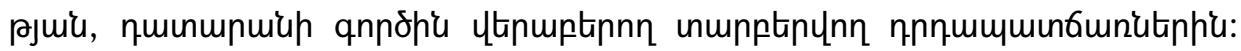

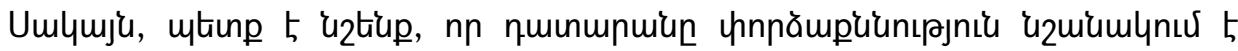

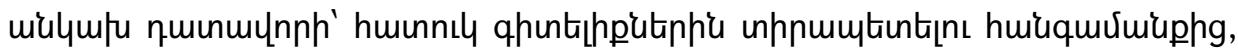

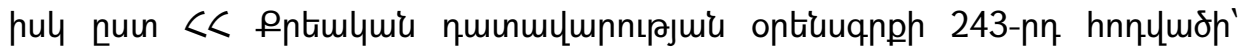

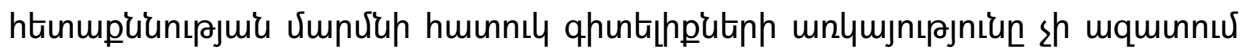

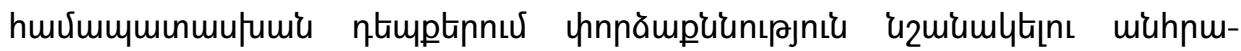
dt2unnıpjnıüng [3]: 


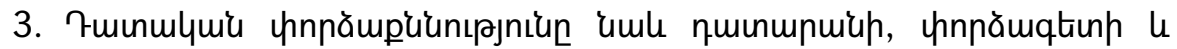

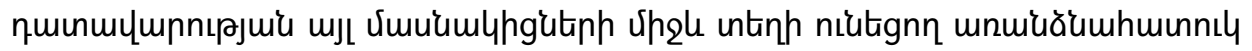

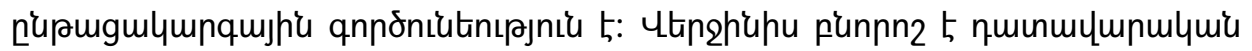

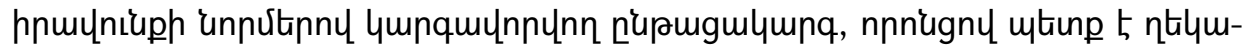

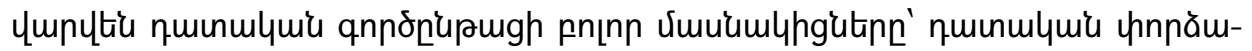

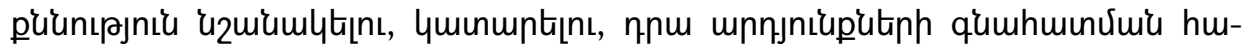

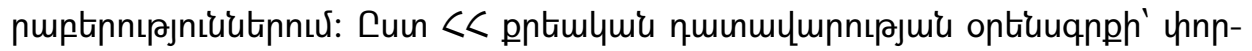

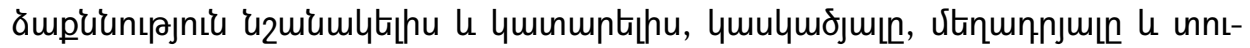

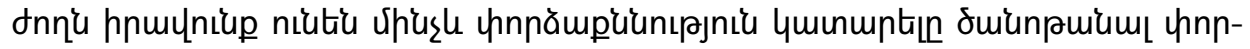

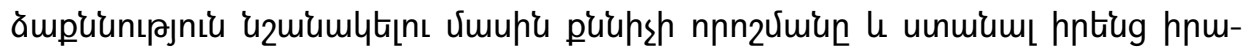

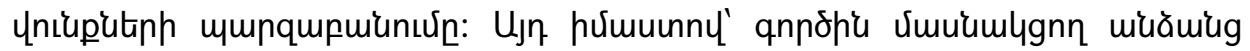

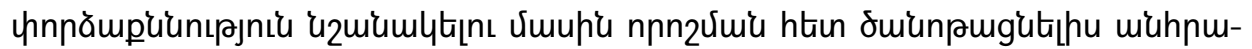

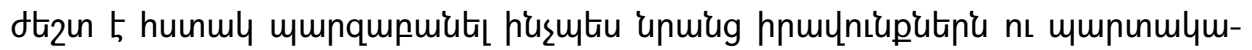

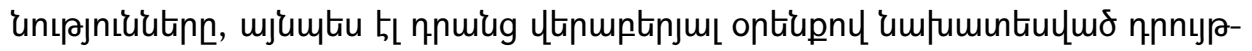

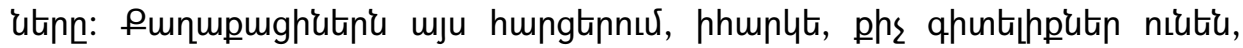

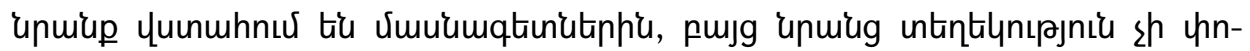

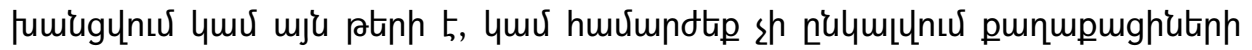

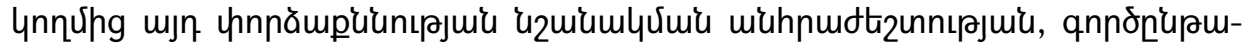

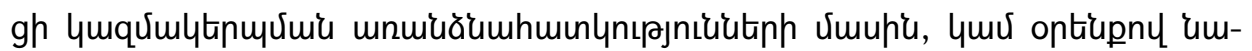

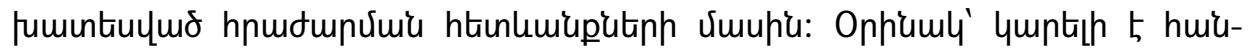

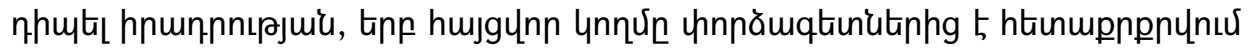

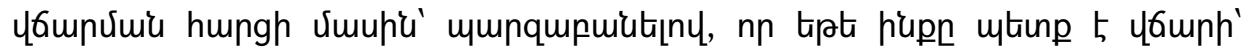

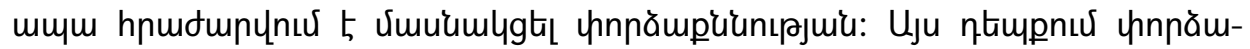

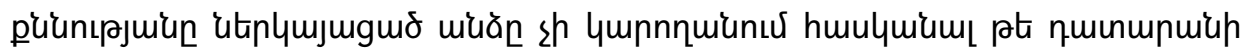

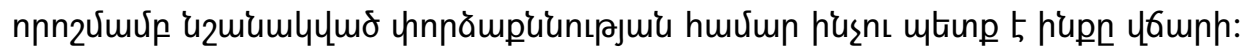

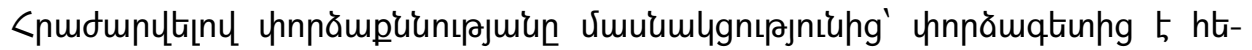

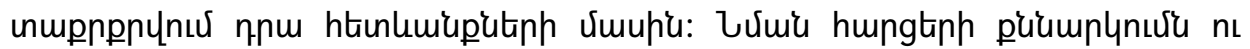

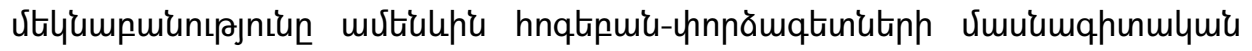

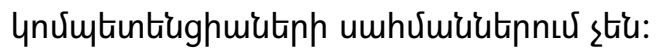

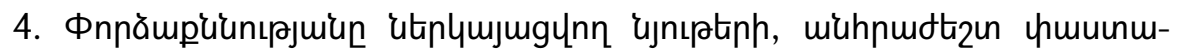

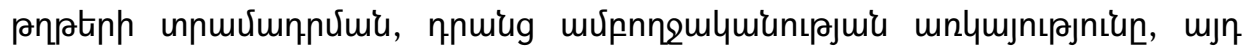

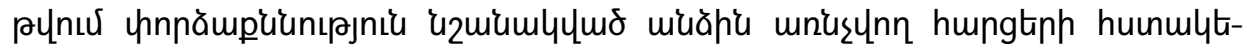

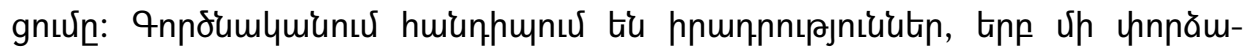

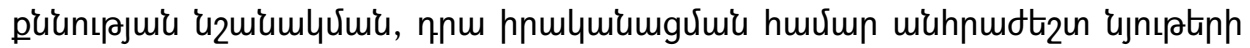

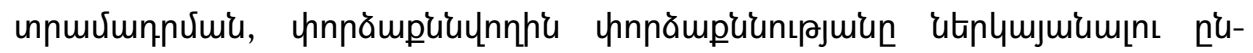

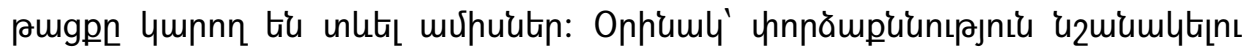

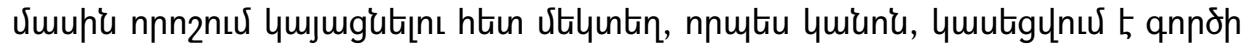

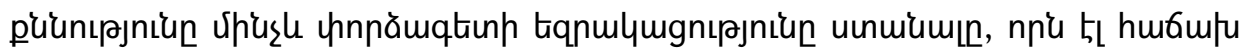

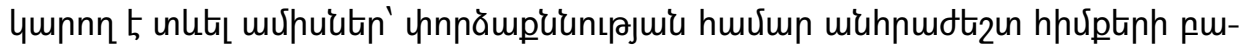

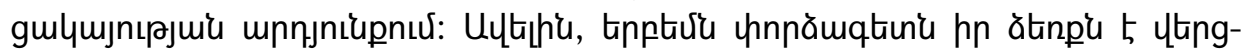




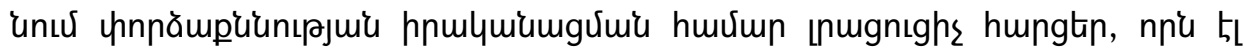

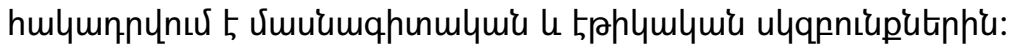

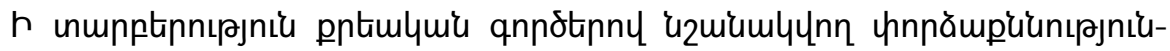

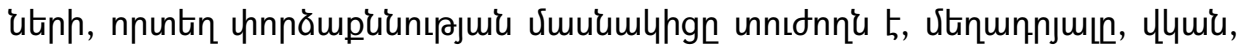

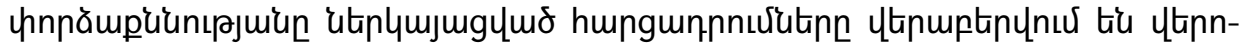

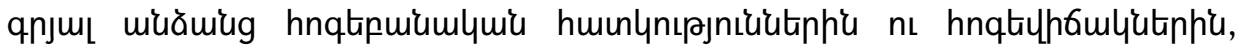

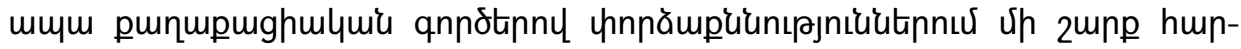

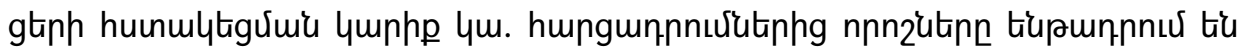

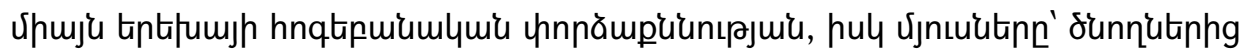

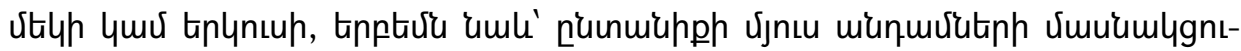

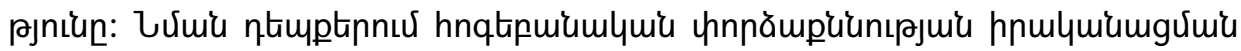

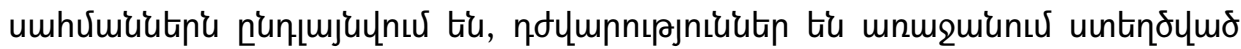

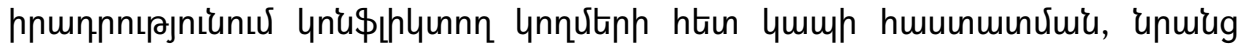

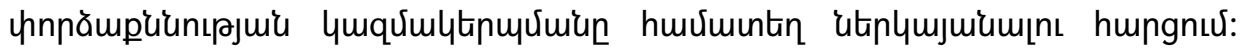

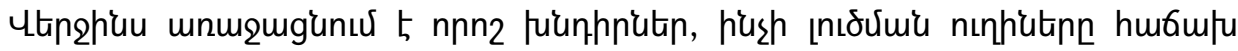

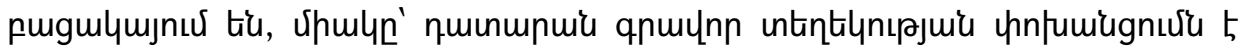

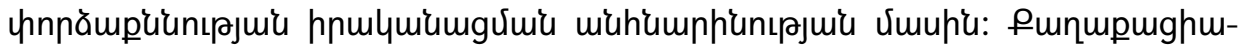

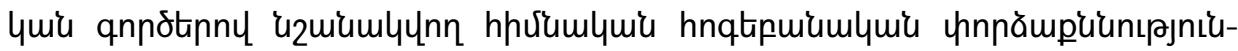

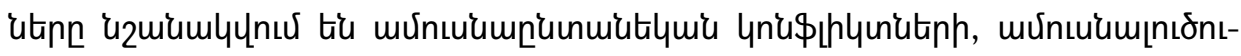

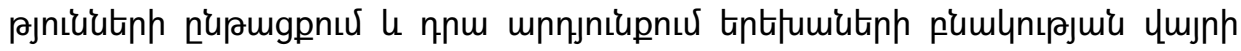

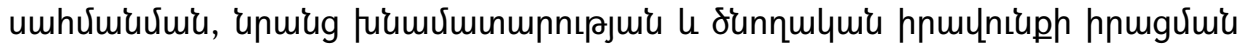

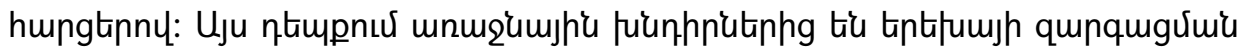

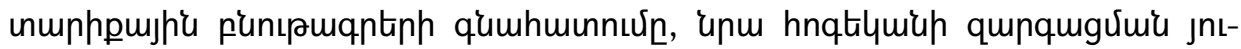

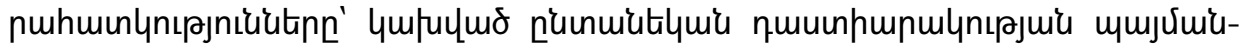

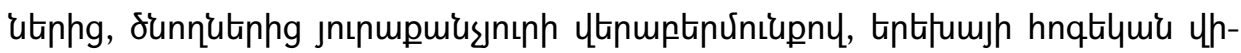

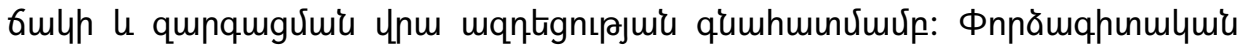

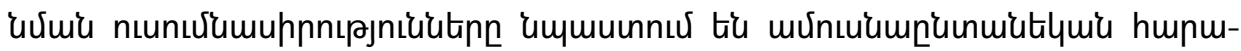

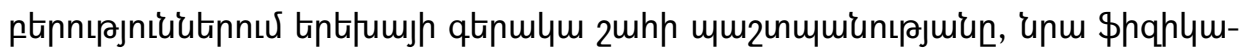

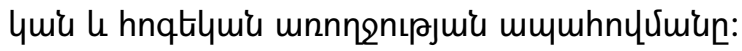

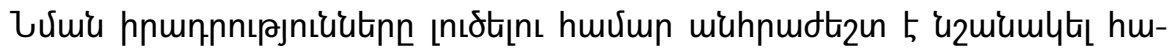

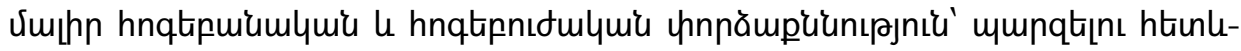
jü huiuquiưưputinn.

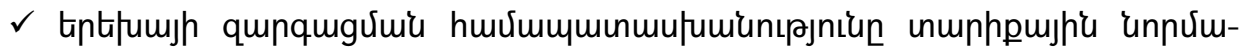

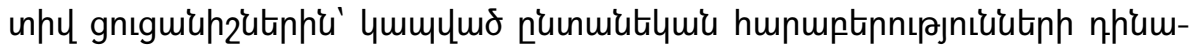
úplumnu,

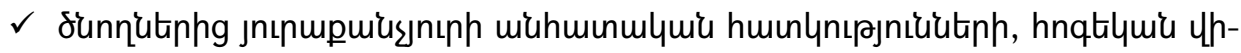

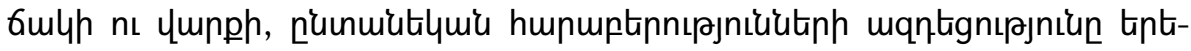

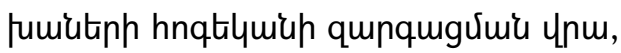




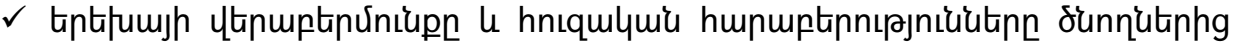

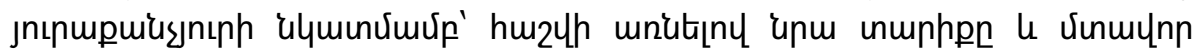
qunqugưu'u vimlympmulu,

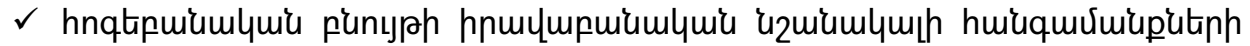

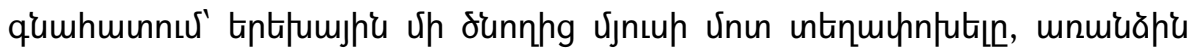

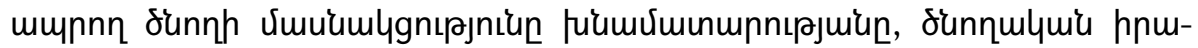

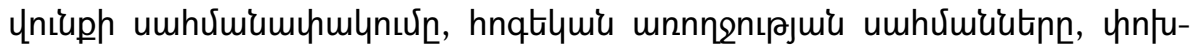

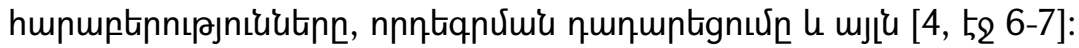

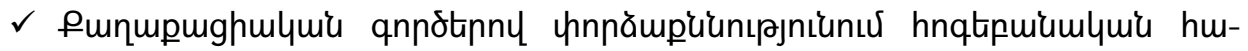

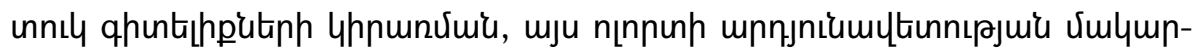

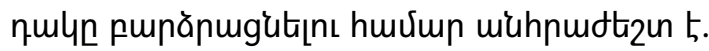

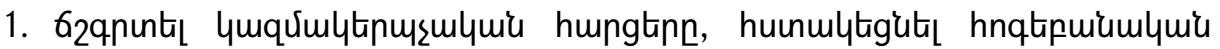

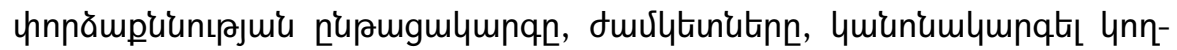

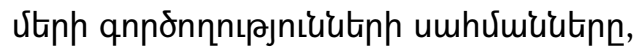

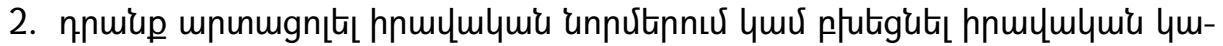
unuutinhn,

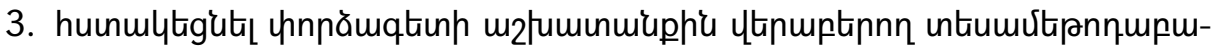
umlymí fưunhnutinn:

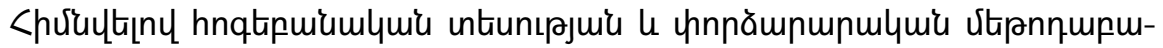

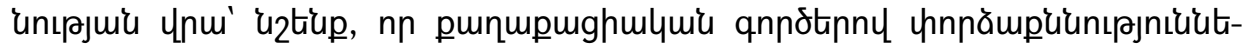

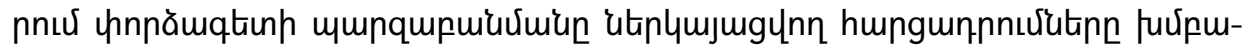

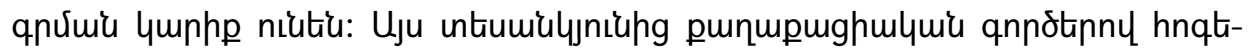

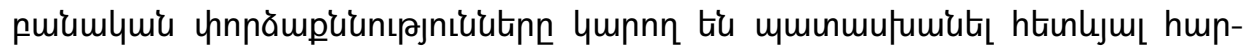
gunnnưututiphu.

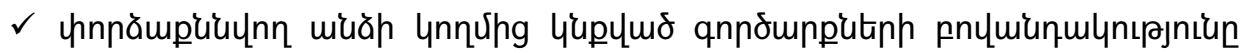

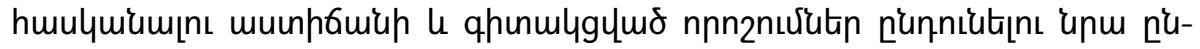

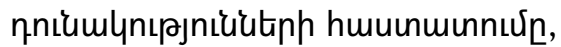

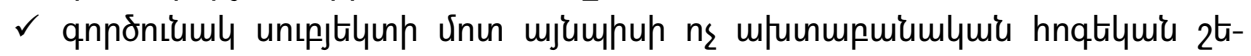

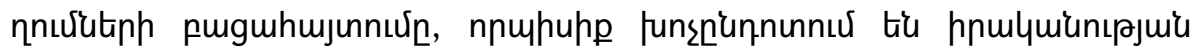
huviumotip mpunmgnulumin,

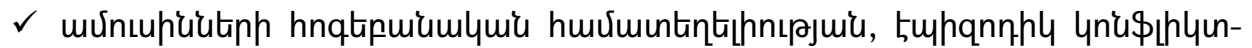

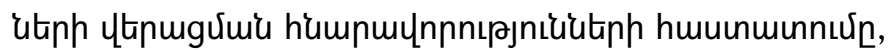

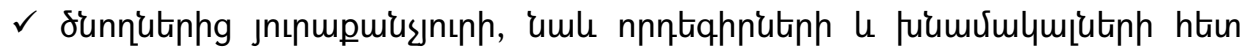

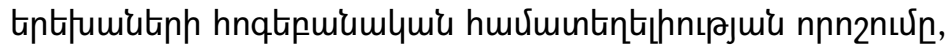

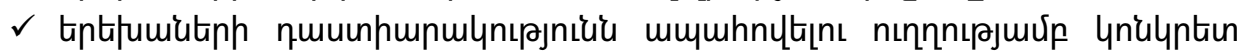

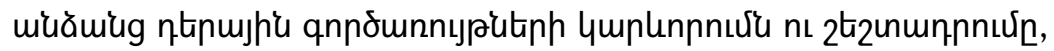

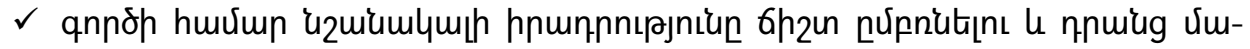

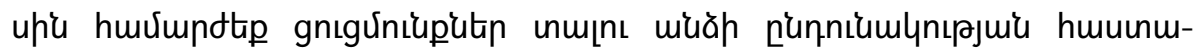
unnuln: 


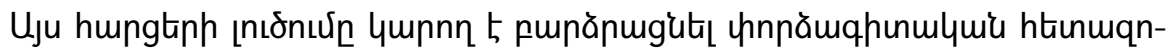

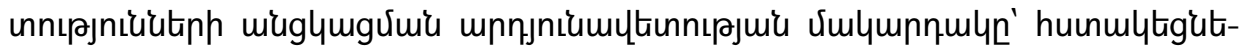

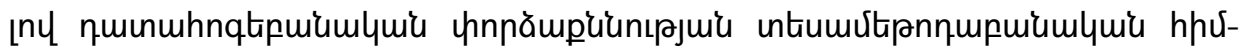

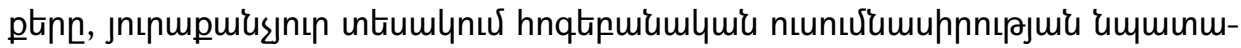

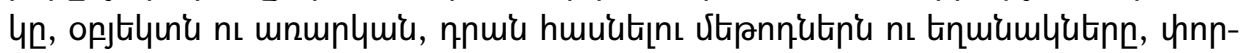

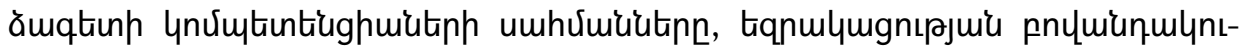

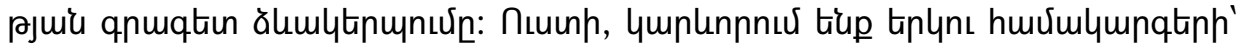

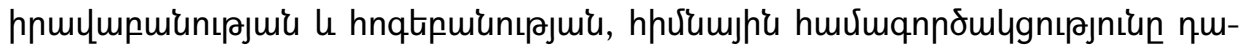

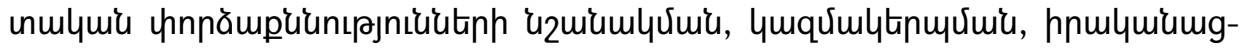

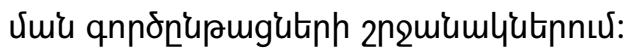

\section{9pulyutunıpjnıtu}

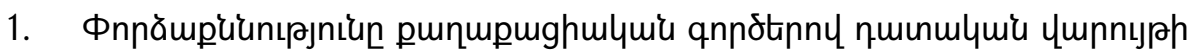

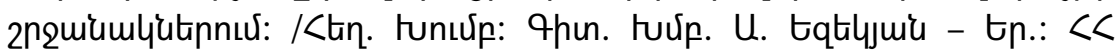

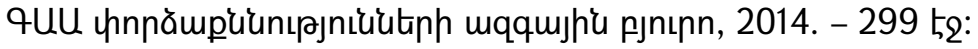

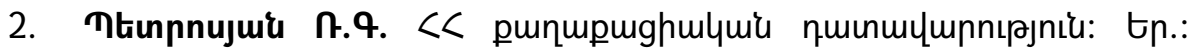
2012, 320 52:

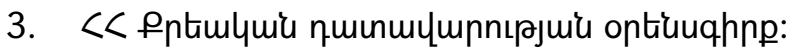
http://www.irtek.am/views/act.aspx?aid=150022

4. Сыропятов О.Г., Дзеружинская Н.А., Солдаткин В.А. Судебная экспертиза психического здоровья в гражданском процессе. ГБОУ ВПО РостГМУ Минздравсоцразвития России, Украинская военномедицинская академия, 2012. - 160 с.

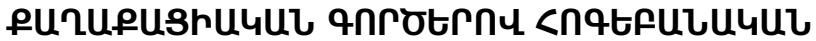

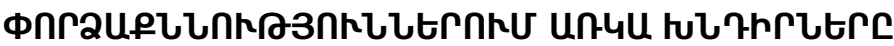

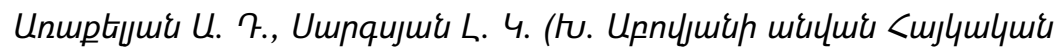

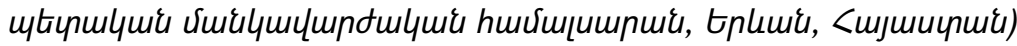

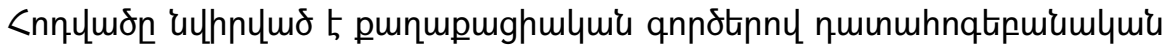

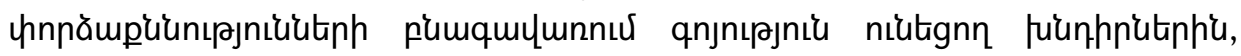

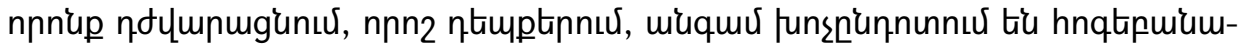

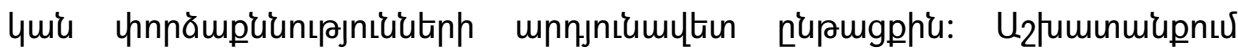

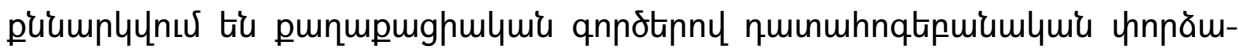

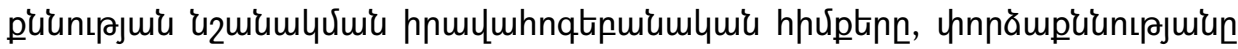

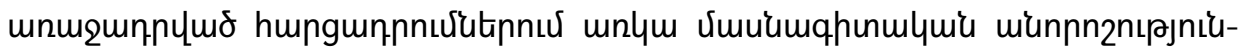

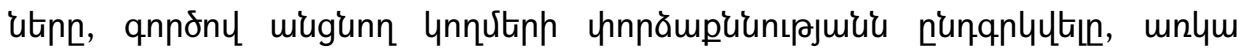

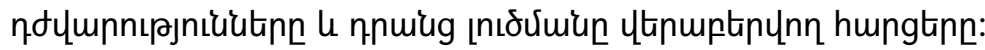




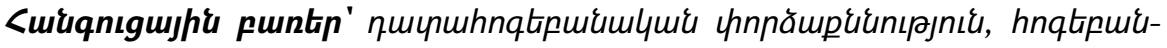

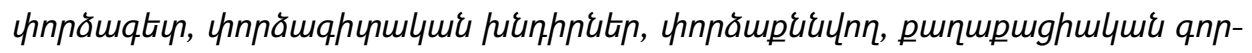

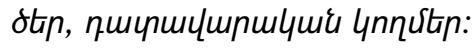

\section{ПРОБЛЕМЫ ПСИХОЛОГИЧЕСКОЙ ЭКСПЕРТИЗЫ ГРАЖДАНСКИХ ДЕЛ}

Аракелян А.Д., Саргсян Л.К. (Армянский государственный педагогический университет им. Х. Абовяна, Ереван, Армения)

В статье предпринята попытка представить существующие проблемы в области судебно-психологической экспертизы по гражданским делам, которые усложняют, а в некоторых случаях препятствуют эффективному процессу психологических экспертиз. В статье рассматриваются правовые и психологические основания назначения психологической экспертизы по гражданским делам, профессиональная неопределенность вопросов экспертизы, существующие трудности и вопросы, связанные с их решением, а также участие сторон в экспертизе.

Ключевые слова: судебно-психологическая экспертиза, психолог-эксперт, экспертные вопросы, испытуемый, судебные стороны, гражданские дела. 